\title{
ВОДА КАК ОСНОВНОЙ КОМПОНЕНТ ЭМУЛЬСИИ СМАЗОЧНО-ОХЛАЖДАЮЩЕЙ ЖИДКОСТИ (СОЖ)
}

Александр КЛЕПИКОВ

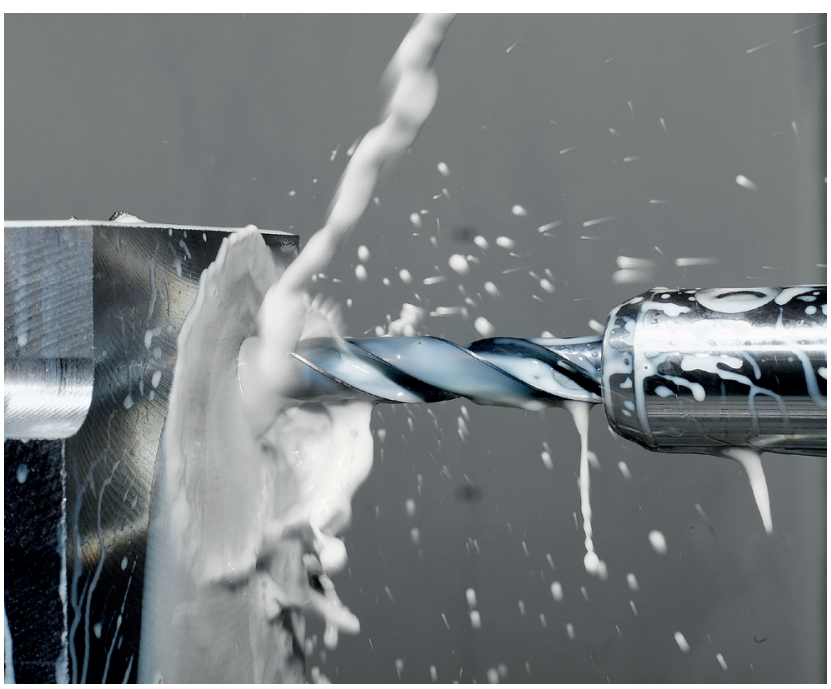

Водосмешиваемые смазочно-охлаждающие жидкости требуют более тщательного контроля по сравнению с масляными. Вызвано это тем, что в их составе может содержаться до 99\% воды. Трудно переоценить влияние состояния какоголибо компонента на технологические и эксплуатационные характеристики всей смеси, если концентрация этого компонента может достигать 99\%. Именно поэтому мы считаем вполне обоснованным написание отдельной статьи об этом удивительном веществе.

Данный материал, в отличие от множества вышедших статей, изданий и даже фильмов о воде, носит не такой обширный характер, а является довольно узконаправленным и прагматичным. Нас интересует, как вода влияет на рабочую жидкость, и, если это влияние негативно, как его снизить или по возможности устранить в условиях предприятия. Итак, чтобы быть уверенными в том, что СОЖ будет выполнять все заявленные функции в течение максимально возможного периода, необходимо понять, что и в каком количестве, кроме молекул $\mathrm{H}_{2} \mathrm{O}$, содержит в себе вода, поступающая в цех металлообработки. Причем обрести это понимание желательно еще до подбора соответствующего технологическому процессу концентрата продукта.

В условиях предприятия можно и нужно измерить следующие физико-химические характеристики воды:

$\rightarrow$ общую жесткость;

$\rightarrow$ водородный показатель $\mathrm{pH}$;

$\rightarrow$ электропроводность;

$\rightarrow$ общее количество бактерий и грибков.

Рассмотрим каждую из перечисленных характеристик несколько подробнее.

\section{ОБЩАЯ ЖЕСТКОСТЬ ВОДЫ}

Общая жесткость воды отражает суммарное содержание растворенных в воде солей кальция, магния и, в гораздо меньшей степени, железа. Самый простой с точки зрения затрат способ измерения жесткости воды - индикаторные полоски со специальным покрытием, изменяющим цвет согласно количеству ионов перечисленных солей (рис. 1). Точность измерения таким путем невелика

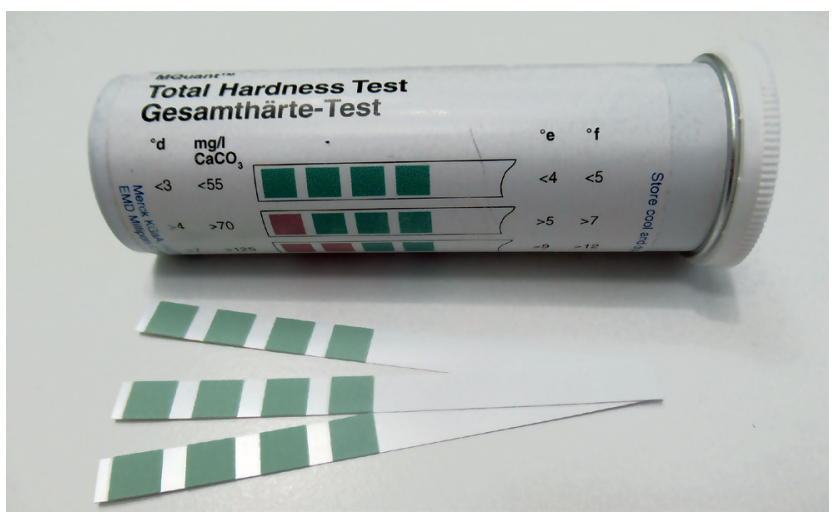

Puc. 1. Индикаторные тест-полоски для определения общей жесткости 
и несколько субъективна, поскольку зависит от восприятия цвета наблюдателем и даже от освещенности в месте измерения. Однако, учитывая довольно широкий диапазон допустимых значений общей жесткости воды у продуктов Castrol, точности тест-полосок вполне достаточно для выбора «кандидата» на испытания или для принятия решения о корректирующих действиях в отношении этого параметра.

Для получения более точных результатов без привлечения специализированной лаборатории используются портативные электронные приборы с ионоселективным электродом. Такие приборы достаточно дороги, и целесообразность их применения в условиях предприятия сомнительна. Отметим, что в настоящее время предлагается множество вариантов относительно недорогих портативных приборов, так называемых солемеров и TDS-метров (TDS - Total Dissolved Solids - общее количество растворенных в воде веществ). Они непригодны для определения общей жесткости воды, поскольку «не отличают» соли жесткости от других солей и растворенных веществ.

Слишком жесткая вода способствует возникновению коррозии и снижает эффективность эмульгаторов, что может спровоцировать дестабилизацию (разделение на фазы) эмульсии, а также образование как трудноудаляемых твердых, так и мазеобразных отложений. Слишком мягкая вода может вызвать повышенное пенообразование при использовании СОЖ, содержащих минеральные масла.

Все водосмешиваемые СОЖ рассчитаны на определенный диапазон жесткости воды. Мы считаем необходимым указывать этот диапазон в техническом описании на каждый продукт. При этом единицы измерения общей жесткости воды в случае наших продуктов - ppm $\mathrm{CaCO}_{3}$ (ppm - parts per million - частиц на миллион; обозначение 1 ppm $\mathrm{CaCO}_{3}$ означает, что в воде содержатся соли жесткости в количестве, эквивалентном одной части карбоната кальция на миллион частей воды). В табл. 1 дано соответствие ppm $\mathrm{CaCO}_{3}$ принятым в РФ и других странах единицам измерения. Для качественной оценки общей жесткости воды можно воспользоваться табл. 2.

Снижение общей жесткости может достигаться добавлением определенных химических реагентов (например, соды), применением установок обрат-

\section{Таблица 1. Соответствие единиц измерения различных стран}

\begin{tabular}{|l|l|l|l|l|l|}
\hline Страна & США & Россия & Германия & Великобритания & Франция \\
\hline Ед. изм. & $\mathrm{ppm} \mathrm{CaCO}_{3}$ & ${ }^{*}$ Ж (мг·экв/л) & ${ }^{*} \mathrm{dH}$ & ${ }^{*} \mathrm{Clark}$ & ${ }^{*} \mathrm{~F}$ \\
\hline Значение & 1 & 0,02 & 0,056 & 0,07 & 0,1 \\
\hline
\end{tabular}

Таблица 2. Общая жесткость воды

\begin{tabular}{|l|l|l|l}
\hline Общая оценка & $\mathrm{ppm} \mathrm{CaCO}_{3}$ & ${ }^{*}$ Clark & ${ }^{*} \mathrm{dH}$ \\
\hline Мягкая & $0-100$ & $0-7$ & $0-5,6$ \\
\hline Умеренно жесткая & $100-200$ & $7-14$ & $5,6-11,2$ \\
\hline Жесткая & $200-300$ & $14-21$ & 11,2-16,8 \\
\hline Очень жесткая & Более 300 & Более 21 & Более 16,8
\end{tabular}

ного осмоса или с помощью ионообменных колонн. Два последних способа кардинально снижают количество солей, что в дальнейшем может потребовать искусственного увеличения жесткости до приемлемой для конкретного продукта. Отметим, что последнее утверждение не касается синтетических СОЖ линейки Castrol Syntilo, которые не имеют склонности к пенообразованию даже в обессоленной воде и при высоких давлениях подачи. Наконец, существует самый простой с точки зрения организации процесса способ снижения жесткости воды разбавить поступающую в цех воду дистиллированной или деминерализованной водой. Такой способ, как правило, применяется для индивидуальных систем подачи. Для централизованных систем емкостью в размере десятков тонн целесообразнее, на наш взгляд, организовать водоподготовку. В пользу этой рекомендации также выступает эффект накопления солей в системе вследствие долива жидкости в качестве компенсации расхода на выпаривание воды или уноса СОЖ со стружкой. На практике мы наблюдали ситуации, когда при начальной общей жесткости воды порядка 250 ppm $\mathrm{CaCO}_{3}$, через шесть месяцев работы количество накопившихся солей жесткости составляло 1270 ppm $\mathrm{CaCO}_{3}$.

Повысить общую жесткость воды несколько проще. Необходимо добавить в воду специальные реагенты, например, кальциевую соль уксусной кислоты (ацетат кальция). Причем, в большинстве случаев достаточно всего $0,1 \%$ этого вещества от объема системы.

\section{ВОДОРОДНЫЙ ПОКАЗАТЕЛЬ РН}

Водородный показатель рН - это мера активности ионов водорода в жидкости, которая количественно выражает ее кислотность. Определяется рН количественным соотношением в воде ионов $\mathrm{H}^{+}$и $\mathrm{OH}^{-}$. Если в жидкости пониженное содержание свободных ионов водорода $\left(\mathrm{H}^{+}\right)$по сравнению с ионами гидроксида $\left(\mathrm{OH}^{-}\right)$, то она будет иметь щелочную реакцию $(\mathrm{pH}>7)$. А при повышенном содержании ионов $\mathrm{H}^{+}$реакция будет кислой 


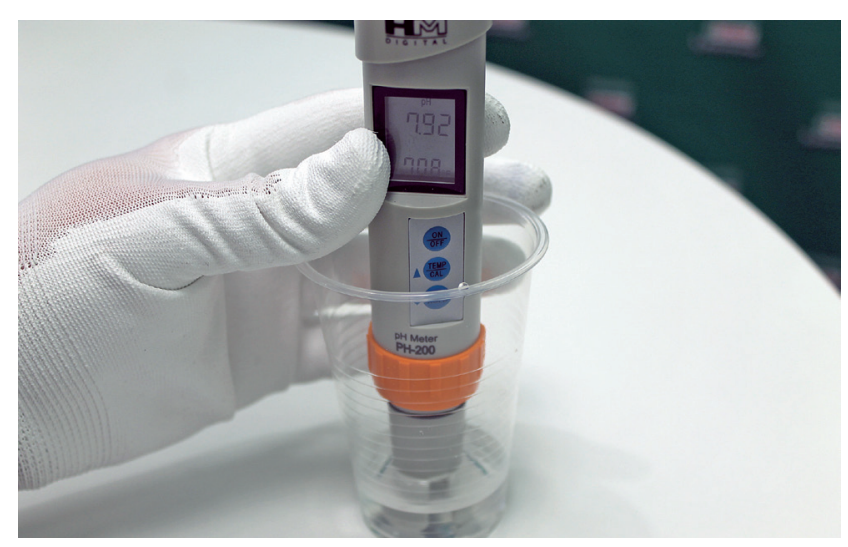

Puc. 2. Портативный прибор для измерения $\mathrm{pH}$

$(\mathrm{pH}<7)$. У условно питьевой водопроводной воды этот показатель обычно около семи единиц, то есть реакция нейтральная. Для измерения $\mathrm{pH}$ имеются относительно недорогие портативные электронные приборы, один из которых показан на рис. 2.

Менее точный, но более доступный способ - применение тест-полосок, однако мы рекомендуем все же использовать электронный прибор. Ведь, помимо измерения «начального» $\mathrm{pH}$, вам потребуется регулярно контролировать этот параметр на протяжении всего периода эксплуатации СОЖ, а для этих целей точности полосок недостаточно. Желательно, чтобы значение водородного показателя используемой воды находилось в диапазоне от 6,5 до 7,5. Если оно отклоняется от этого диапазона в сторону увеличения кислотности, щелочной буфер СОЖ частично потеряет свою активность еще до начала работы продукта. В результате СОЖ будет иметь меньший запас веществ, нейтрализующих кислые продукты жизнедеятельности бактерий, и химическая коррозия не заставит себя долго ждать. Напротив, если вода имеет щелочную реакцию, велика вероятность появления раздражения на коже операторов станка. Поэтому, если $\mathrm{pH}$ значительно отклоняется от оптимального диапазона, необходимо нейтрализовать воду или пересмотреть источник водозабора. Иногда самым простым решением является разбавление дистиллированной водой.

\section{ЭЛЕКТРОПРОВОДНОСТЬ}

Электропроводность показывает общее количество всех электролитов в жидкости, в том числе солей жесткости. Электролиты проводят электрический ток, поэтому следствием их высокого содержания в жидкости может стать электрохимическая коррозия. Кроме того, на эмульгаторы негативно влияют не только соли жесткости, но и другие соли, ионы которых могут реагировать с некоторыми

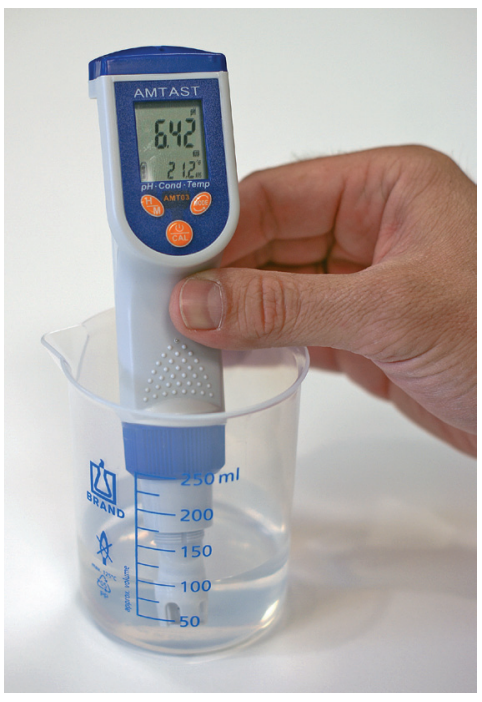

Puc. 3. Портативный прибор для измерения $\mathrm{pH}$, электропроводности и TDS

типами эмульгаторов, «выключая» их из работы. В конечном итоге, это может привести к разделению эмульсии на водную и масляную фазы, а значит, к необходимости ее замены. Для целей контроля качества воды для приготовления СОЖ и мониторинга состояния самой СОЖ вполне подходят недорогие портативные приборы, один из которых показан на рис. 3.

Поскольку и жесткость, и электропроводность в сущности показывают содержание ионов солей, методы коррекции этих характеристик совпадают. Отметим только, что повышение электропроводности в нашем случае приводит только к негативным результатам.

\section{КОЛИЧЕСТВО БАКТЕРИЙ И ГРИБКОВ}

Количество бактерий и грибков измеряется путем посева на специальных питательных средах на осно-

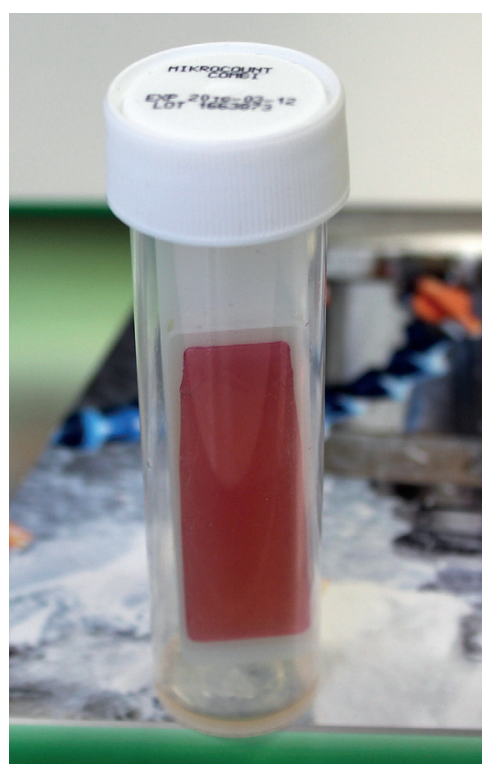

Puc. 4. Погружной слайд для измерения количества бактерий и грибков ве агара, нанесенных на удобные для использования приспособления, так называемые д и п - с л а й д ы (рис. 4). Определение этого параметра особенно важно, если для приго т о в л е н и я рабочей эмульсии предполагается забор воды из природных источников, а не из водопроводной сети. Количество бактерий и грибков в смазочно-охлаждающей жидкости напрямую влияет на срок ее эксплуа- 


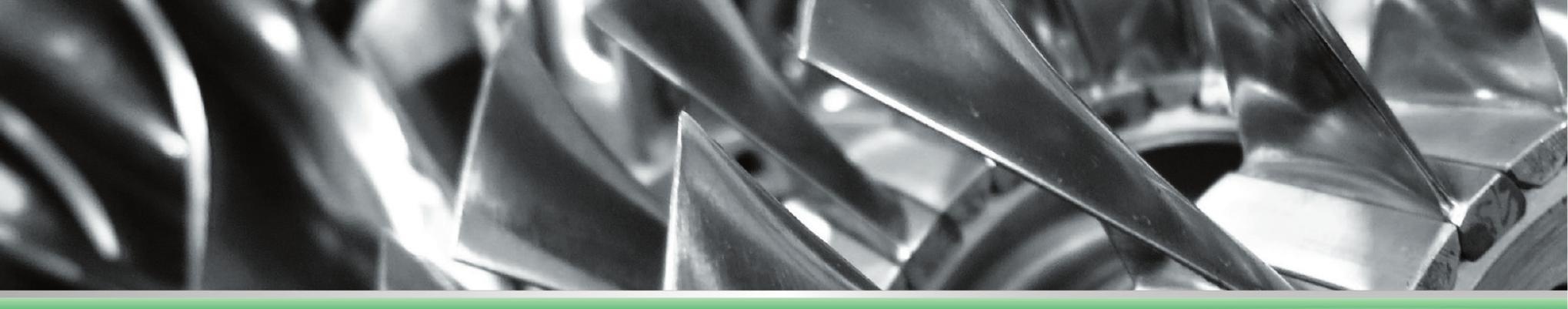

\section{ТЕХНОЛОГИЯ CASTROLXBB}

БЕЗОПАСНОСТЬ БЕЗ НОМПРОМИССОВ

БЕЗ БИОЦИДОВ БЕЗ БОРА
Более 100 лет Castrol производит и поставляет высонозффективные смазочные материалы и технологические жидности для промышленного оборудования. Инженеры Castrol осознают, какую ценность для машиностроительных предприятий представляет возможность высоконачественной, безопасной экономичной обработки металлов. Именно поэтому наши специалисты разработали широний спектр смазочно-охлаждающих жидностей, включая две новые линейки на базе инновационной технологии Castrol XBB.
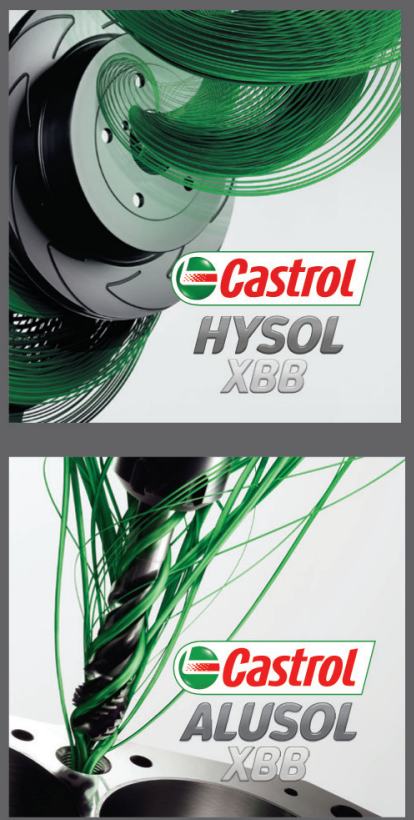

Частицы обрабатываемого металла могут приводить к нарушению стабильности эмульсии как сами по себе, так и являясь очагами для размножения микроорганизмов. Новые продукты линейки Hysol содержат компоненты, позволяющие сохранить стабильность жидкости длительное время даже в таких условиях
Преимущества

- Не содержит хлор, бор и выделяющие формальдегид вещества

- Содержит компоненты, способствующие улучшению качества поверхности наряду с увеличением стойкости инструмента

- Отличается высокой механической и биологической стабильностью

- Характеризуются низким вспениванием (при соблюдении рекомендаций для смешения эмульсии, учитывающих качество используемой воды)

- Обеспечивает отличное смачивание

- Не оказывает влияния на поверхности оборудования и оснастки

Спецификации и одобрения: Airbus: AIMS12-10-000 (technical specification); AIMS12-10-001 (material specification); Safran Group: D-180516-03944; BAMS 569-001 Version B;

При обработке алюминия и его сплавов, включая авиационные, существует тенденция к образованию наростов на режущем инструменте и изменению его геометрии. Композиция линейки Alusol XBB, разработанная C целью увеличения срока службы инструмента, обеспечивает чистоту инструмента и деталей одновременно с улучшением качества обрабатываемой поверхности.

\section{Преимущества}

- Высокоэффективная полусинтетическая смазочно-охлаждающая жидкость

- Не содержит бор, хлор и выделяющие формальдегид вещества

- Компоненты, входящие в ее состав, способны улучшить эффективность обработки в сочетании с улучшением качества обрабатываемой поверхности

- Демонстрирует превосходную стабильность

Спецификации и одобрения: Safran Group: D-110416-03004

\section{СИНТЕТИЧЕСКИЕ СОЖ CASTROLSYNTILO}

Смазочно-охлаждающие жидкости Castrol с успехом используются ведущими мировыми производителями. Продукты линейки синтетических водосмешиваемых СОЖ Castrol Syntilo по биостойности и механической стабильности значительно превосходят жидкости с содержанием минерального масла.

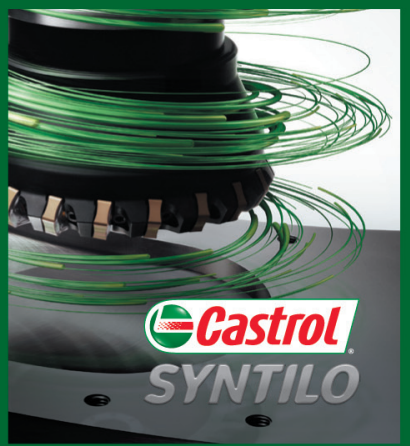

Высокоскоростная обработка приводит к экстремальным температурам на режущей кромке, иногда превышающим $1000^{\circ} \mathrm{C}$ Такие температуры негативно влияют как на деталь, так и на обрабатывающий инструмент. Технологии Syntilo позволяют охлаждать зону резания не хуже воды, одновременно смазывая режущую кромку как традиционная эмульсия.
Преимущества

- рН-нейтральны, не содержат бор и выделяющие формальдегид вещества

- Специально разработаны с учетом применения в большинстве операций обработки резанием различных металлов, включая авиационные сплавы титана и алюминия

- Отличные смазывающие и охлаждающие свойства

- Низкая склонность к вспениванию даже при высоких давлениях подачи и смешивании с мягкой водой

- Значительно более стойкие к биопоражению по сравнению с СОЖ с содержанием минерального масла

Спецификации и одобрения: Airbus: 2006-19689-DCR/SP/SE; Boeing: BAC 5008; Bombardier: BAMS 569-001; Messier-Dowty; Pratt and Whitney: PMC 9398 Rev. C; Safran Group: PCS-4002 
Таблица 3. Предельные значения параметров качества воды

\begin{tabular}{|l|l|l|}
\hline Показатель & Единица измерения & Диапазон \\
\hline Общая жесткость & ppm СаСО & См. техническое описание продукта \\
\hline Уровень рH & - & $6,5-7,5$ \\
\hline Электропроводность & мкСм & До 800 \\
\hline Число бактерий & $\begin{array}{l}\text { Количество (мл) } \\
\text { жидкости }\end{array}$ & До 103 \\
\hline Число грибков & - & $\begin{array}{l}\text { См. инструкцию к дипслайдам, } \\
\text { определение «незначительное } \\
\text { поражение» }\end{array}$ \\
\hline
\end{tabular}

тации, поэтому измерение начальных значений нельзя игнорировать. Если число бактерий и/или грибков превышает норму, необходимо провести обработку воды бактерицидом и/или фунгицидом. В любом случае забор воды для приготовления СОЖ лучше производить из водопроводной сети.

В табл. 3 приведены ориентировочные предельные значения рассмотренных параметров качества воды, используемой для приготовления эмульсии или раствора смазочно-охлаждающей жидкости. Основываясь на опыте, можно с абсолютной уверенностью сказать, что каждый участок металлообработки требует индивидуального подхода в отношении выбора СОЖ, ее приготовления, мониторинга и сервиса. Именно поэтому мы всегда готовы помочь заказчикам на каждом этапе эксплуатации наших продуктов. Рекомендации вы можете получить в техническом отделе.

Обратите внимание, что каждый из рассмотренных параметров равнозначен по важности и, в большей или меньшей степени, влияет на остальные, изменяясь в процессе работы уже готового продукта.

Кроме того, все эти параметры контролируются и в работающей эмульсии, о чем мы поговорим в одной из следующих статей.

На этом наша статья завершается. В следующем номере мы постараемся доступно рассказать о подготовке системы к замене водосмешиваемой смазочно-охлаждающей жидкости и о приготовлении рабочей эмульсии.

\section{КЛЕПИКОВ Александр -}

технический консультант по маслам для промышленных предприятий компании Castrol Россия

\section{КНИГИ ИЗДАТЕЛЬСТВА «ТЕХНОСФЕРА»}

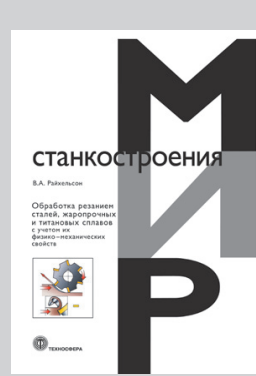

Цена 1210 руб.

\section{ОБРАБОТКА РЕЗАНИЕМ СТАЛЕЙ, ЖАРОПРОЧНЫХ И ТИТАНОВЫХ СПЛАВОВ С УЧЕТОМ ИХ ФИЗИКО- МЕХАНИЧЕСКИХ СВОЙСТВ \\ M.:TЕХHOСФЕРА 2018. $-508 \mathrm{C}$. ISBN 978-5-94836-476-6}

\section{Райхепьсон B.A.}

\footnotetext{
В книге освещены основные виды механической обработки резанием современных конструкционных сталей, жаропрочных и титановых сплавов лезвийными инструментами: точение, строгание, сверление, фрезерование, протягивание, разрезка заготовок и прорезка пазов.

Книга содержит большой научно-практический и справочный материал, рассчитана на инженернотехнических работников предприятий машиностроения, авиакосмической отрасли, энерго- и автостроения, оборонной промышленности. Она также послужит учебным пособием для студентов и преподавателей высших и средних учебных заведений машиностроительных специальностей.
} 


\section{ИЗДАТЕЛЬСТВО «ТЕХНОСФЕРА» ПРЕДСТАВЛЯЕТ КНИГУ:}

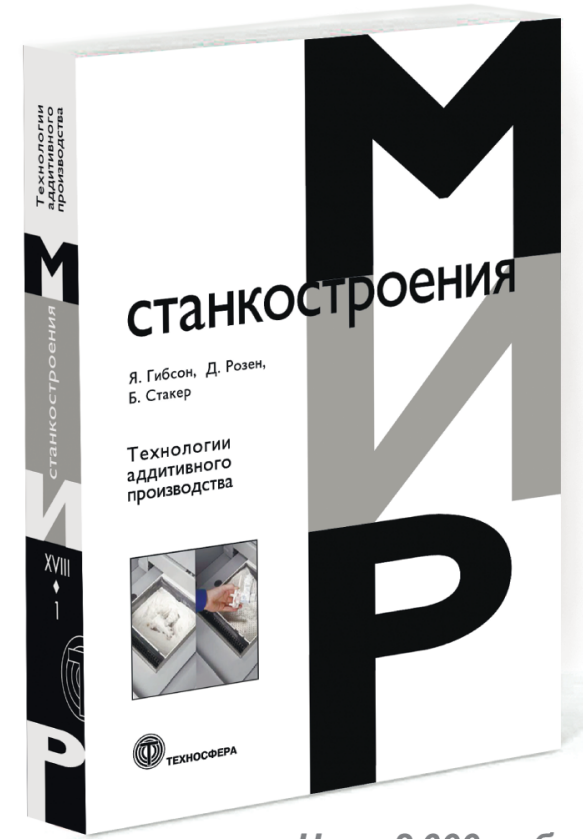

Цена 2600 руб.

Ян Гибсон, Давид Розен, Брент Стакер

ТЕХНОЛОГИИ АДДИТИВНОГО ПРОИЗВОДСТВА. Трехмерная печать, быстрое прототипирование и прямое цифровое производство

Перевод с англ. книги издательства «Springer» под ред. д.ф.-м.н., проф. И.В. Шишковского M.: TEXHOCФЕРA, 2016. - 656 c. ISBN 978-5-94836-447-6

\section{Предисловие к русскому изданию}

Я был очень рад, когда услышал, что профессор Игорь Шишковский будет научным редактором русского издания нашей монографии. Обладая многолетним и богатым опытом в данной области, этот известный ученый и педагог сможет гарантировать как техническую точность, так и ясность изложения. Поскольку русский язык является одним из самых распространенных языков в мире, этот перевод позволит значительно расширить аудиторию, которая сможет впервые получить доступ к данной информации. Я надеюсь, что исследователи, студенты и преподаватели найдут эту книгу прекрасным дополнением к своей коллекции, и что она расширит их познания в быстро развивающихся областях аддитивных технологий.

Брент Стакер профессор, университет Луисвилля (Кентукки, США)

\section{Содержание}

\section{Предисловие}

Глава 1. Введение и описание основных принципов Глава 2. Развитие технологий АП

Глава 3. Общая последовательность процесса АП Глава 4. Процесс фотополимеризации в ванне Глава 5. Плавление порошков в сформированном слое Глава 6. Экструзионные системы

Глава 7. Распыление материала методом струйной печати Глава 8. Распыление связующего для струйной печати Глава 9. Процессы ламинирования листовых (слоистых) материалов
Глава 10. Процессы направленного энерговклада Глава 11. Технологии прямой записи

Глава 12. Преимущества бюджетных систем АП

Глава 13. Руководство по выбору процесса

Глава 14. Постобработка

Глава 15. Задачи программного обеспечения в АП

Глава 16. Прямое цифровое производство

Глава 17. Проектирование для АП

Глава 18. Быстрое изготовление инструмента

Глава 19. Применения АП

Глава 20. Возможности для бизнеса и будущее АП

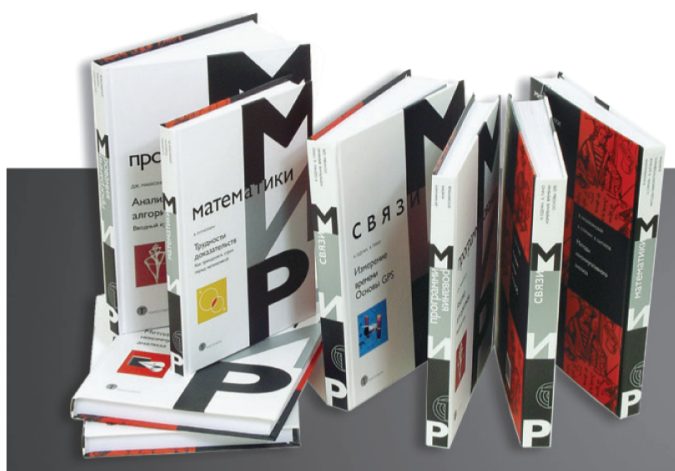

ИНФОРМАЦИЯ О НОВИНКАХ: www.technosphera.ru Как заказать наши книги?

По почте: 125319, Москва, а/я 91 По факсу: +7 495 956-33-46 E-mail:knigi@technosphera.ru sales@technosphera.ru 